\title{
FlashMath: O jogo para o ensino de operações lógicas e matemáticas
}

\author{
Robison F. Mendes Junior ${ }^{1}$, Félix Gustavo de A. Vieira ${ }^{2}$, Evaldinolia G. Moreira ${ }^{2}$ \\ ${ }^{1}$ Curso de Sistema de Informação - Instituto Federal de Educação, Ciência e Tecnologia \\ do Maranhão (IFMA) \\ Av. Getúlio Vargas - 65030-005 - São Luis - MA - Brazil \\ ${ }^{2}$ Departamento de Computação - Instituto Federal de Educação, Ciência e Tecnologia \\ do Maranhão (IFMA) \\ robisonfmendes@gmail.com, gustavovieira1945@gmail.com, \\ evaldinolia@gmail.com
}

\begin{abstract}
Resumo. O software, chamado FlashMath, tem como objetivo apresentar aos alunos do curso técnico em informática ou estudantes que tenham interesse em ingressar em cursos relacionados, o conhecimento de lógica de programação, tendo como base principal os conceitos de Álgebra de Boole e Operações Matemáticas e Lógicas. Esta aplicação está sendo desenvolvida para os principais dispositivos móveis, tais como, tablets e smartphones. O game ensina elou aprimora, através de jogos casuais e educativos, técnicas de raciocínio lógico aos usuários, de maneira rápida, divertida e desafiadora, possibilitando uma forma diferente e atrativa de praticar a temática apresentada.
\end{abstract}

\section{Cenário de uso}

Ensinar lógica de programação tem se tornado um grande desafio para os professores da área de computação. O uso de ferramentas como VisualG permitem não só visualizar o resultado do algoritmo, como também o fluxo de execução e a dinâmica de mudanças nos valores das variáveis (teste de mesa), tornando alguns conceitos básicos (a exemplo: variável, entrada e saída de dados) mais claros. A utilização de tais instrumentos ocorre como reflexo da ausência de disciplinas que envolvam Filosofia ou Álgebra Booleana nos currículos da maior parte das escolas, implicando no fato dos estudantes cursarem a disciplina Algoritmos sem seu pré-requisito fundamental: a Lógica (Koliver, 2004). Não somente a lógica utilizada em nosso dia-a-dia em cada tomada de decisão ou escolha realizada, mas a lógica matemática, que constitui o alicerce para a lógica de programação, a qual tem se tornado significativamente difícil em um nível introdutório, no qual os estudantes carecem tanto de maturidade matemática, quanto de um entendimento básico da própria disciplina.

Além disso, o problema se alastra quando se compreende que os alunos que cursam essa disciplina não conseguem se adaptar ao desenvolver esse raciocino, por estarem acostumados a decorar o conteúdo, e faltando a eles também a motivação, consequência do seu despreparo e desânimo, passam a enxergar a disciplina como um empecilho difícil de superar (Rodrigues, 2002). 
VII Congresso Brasileiro de Informática na Educação (CBIE 2018)

Anais dos Workshops do VII Congresso Brasileiro de Informática na Educação (WCBIE 2018)

Para esta realidade, o software busca ser um instrumento lúdico e desafiador para os alunos do curso técnico em informática ou estudantes que tenham interesse em ingressar em programação de computadores, na disciplina de algoritmos e lógica de programação, através do exercício do que foi explanado em sala de aula para os conteúdos de Álgebra Booleana e Aritmética, básicos para o raciocínio lógico computacional.

\section{Desenvolvimento}

O processo de desenvolvimento do software se iniciou na organização dos principais elementos da lógica de programação e da álgebra aritmética e identificou-se também, que a melhor maneira de abordar esses elementos e cumprir o propósito da aplicação, seria através da gamificação desses conhecimentos, em diferentes modos de jogo 2D para dispositivos móveis. Logo após, foi realizada a prototipação das telas e escolha do Unity, um motor de jogos e uma IDE criado pela Unity Technologies, com várias funcionalidades que permitem um melhor desenvolvimento de uma aplicação 2D e 3D para várias plataformas, dentre elas dispositivos móveis. Sua implementação é através de scripts nas linguagens de programação C\# e/ou JavaScript. Por fim, foi feita a construção do software na ferramenta, codificada as animações e efeitos dentro do software, e implantado o sistema de recompensas. Atualmente a aplicação encontra-se em processo de testes para sua conclusão, aplicação e possível comercialização.

\section{Apresentação do Software}

Ao iniciar o software, o usuário conta com uma tela inicial apresentando o nome da aplicação e sua introdução.
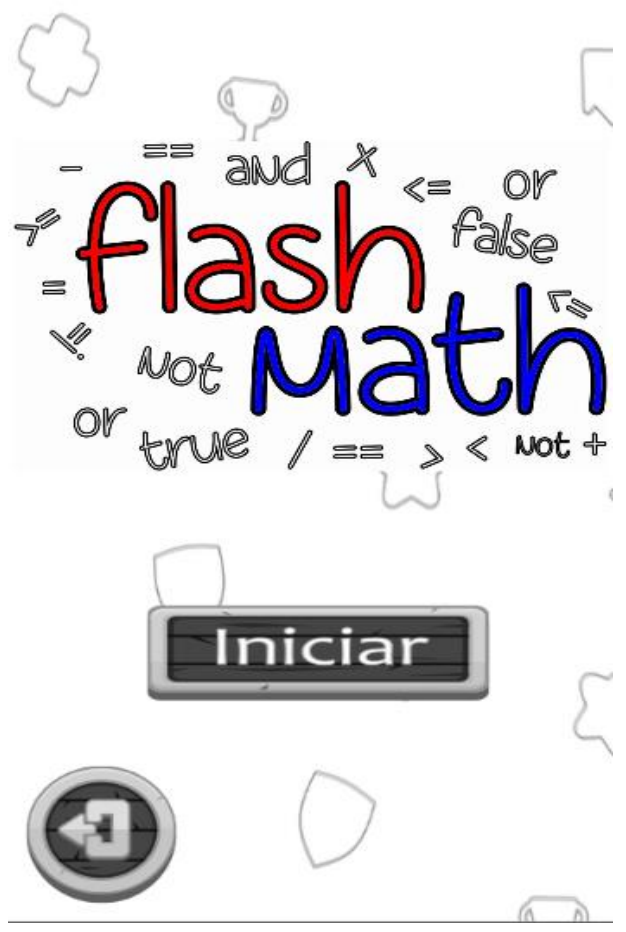

Figura 1. Tela Principal do Software. IFMA, 2016 
VII Congresso Brasileiro de Informática na Educação (CBIE 2018)

Anais dos Workshops do VII Congresso Brasileiro de Informática na Educação (WCBIE 2018)

Ao passar da tela inicial, o aluno (usuário) conta com dois modos de jogo, uma breve explicação dos temas abordados e como aprimorar esses conhecimentos através dos mesmos.

O primeiro modo a ser apresentado é modo Precisão, que propõe exercitar a resolução de expressões aritméticas. Neste modo, o usuário terá 20 segundos para responder as expressões aritméticas que lhes serão apresentadas. Durante este tempo, o usuário não poderá errar nenhuma expressão, exercitando a precisão e senso de atenção do mesmo. $\mathrm{O}$ grau de dificuldade das expressões vai aumentando à medida que o usuário acerta as expressões, estimulando a utilização do raciocínio rápido, além de conceitos referentes ao pensamento computacional. Ao errar alguma das expressões ou ultrapassar o tempo estabelecido, usuário perde o jogo, devendo recomeçá-lo para ultrapassar os desafios e progredir em seu aprendizado.

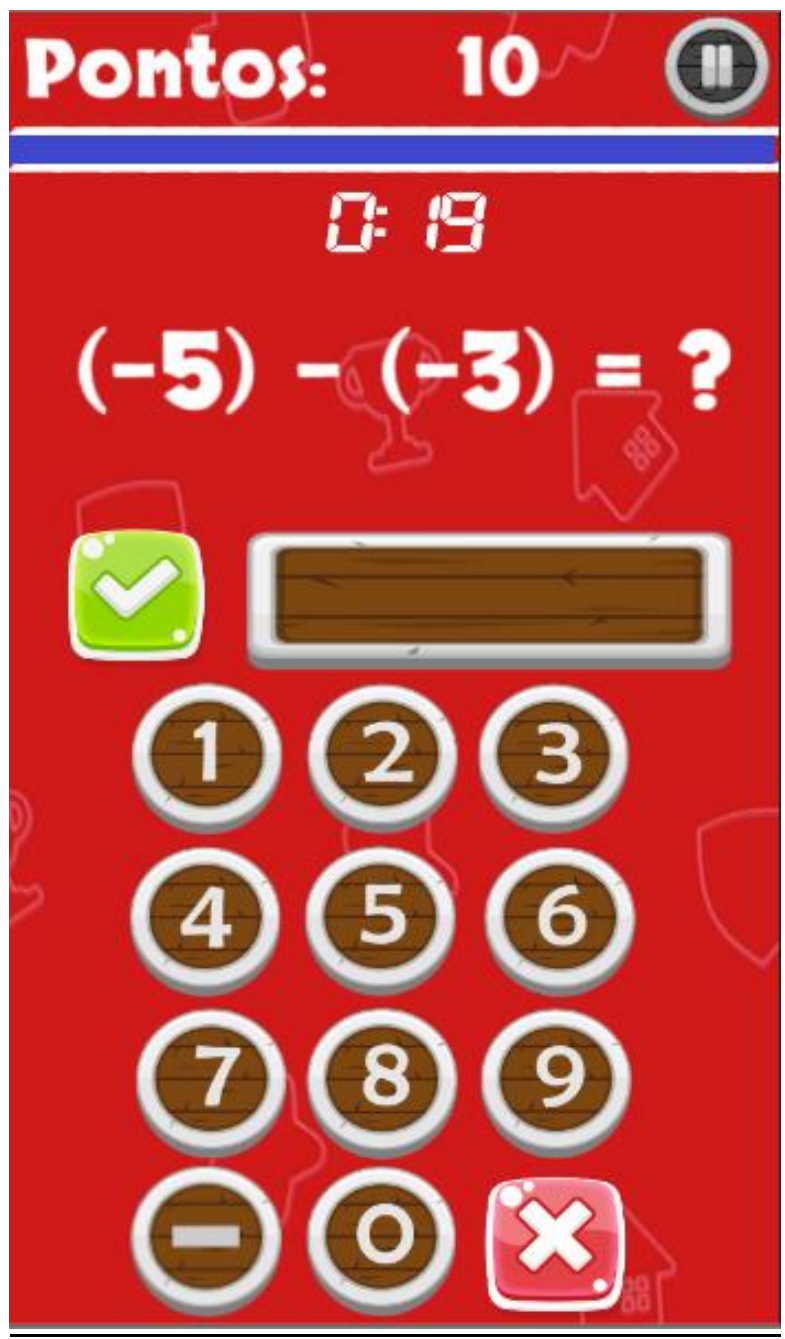

Figura 2. Tela de Jogo do modo Precisão. IFMA, 2016

O próximo modo é chamado Sagacidade, que em seu cerne busca exercitar as expressões de Álgebra Booleana nas linguagens de programação. O usuário dispõe de 20 segundos para resolver as questões lógicas que lhes serão apresentadas, verificando 
VII Congresso Brasileiro de Informática na Educação (CBIE 2018)

Anais dos Workshops do VII Congresso Brasileiro de Informática na Educação (WCBIE 2018)

se apresentam resultados verdadeiros ou falsos. Assim como no modo Precisão, no modo Sagacidade, as expressões crescem em dificuldade ao longo do jogo, utilizando-se de elementos da programação, como operadores relacionais, variáveis e operadores lógicos. Neste modo de jogo, o usuário possui um sistema com 3 vidas, que são perdidas quando este responde às questões de forma incorreta ou ultrapassa o tempo, perdendo assim o jogo.

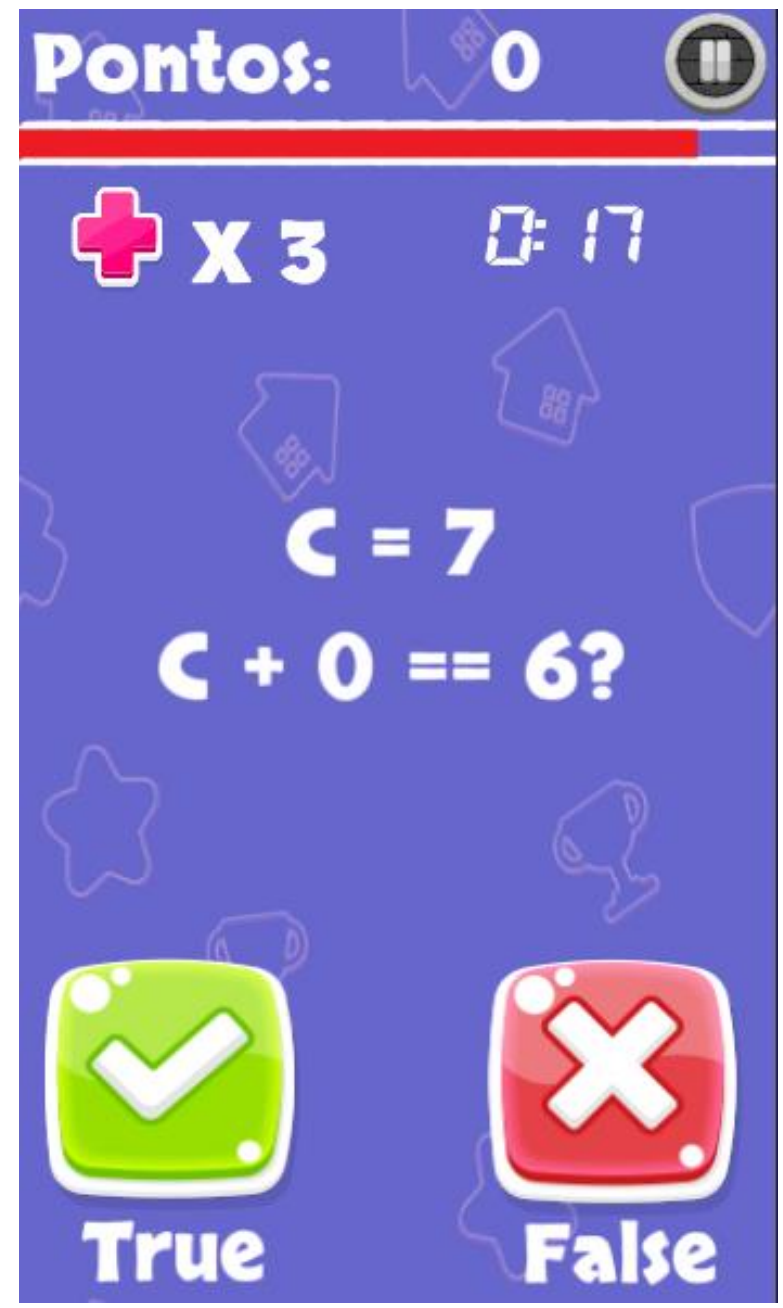

Figura 3. Tela de Jogo do modo Sagacidade. IFMA, 2016

Visando um melhor entendimento do funcionamento do jogo, um vídeo acessível neste link: https://1drv.ms/v/s!AtnjAbHpC0tCgeU5Pgb1iSrh6qmtmw curto se dispõe a elucidar exemplificando o seu uso.

\section{Processo de instalação}

Passo 1) Ter em mãos um aparelho com sistema operacional Android com os requisitos listados acima.

Passo 2) Baixar o arquivo .apk no link:

https://1drv.ms/u/s!AtnjAbHpC0tC0gapRQlnJH1MeIn9 ou selecionar no arquivo que foi descompactado.

Passo 3) Transfira este arquivo para o seu aparelho. 
VII Congresso Brasileiro de Informática na Educação (CBIE 2018)

Anais dos Workshops do VII Congresso Brasileiro de Informática na Educação (WCBIE 2018)

Passo 4) Com o arquivo no celular você deve acessar Configurações> Segurança e habilitar o opção Fontes Desconhecidas.

Passo 5) Agora com seu gerenciador de arquivos procure pelo APK que você copiou. Caso não possua um gerenciador de arquivos é necessário baixar algum na Play Store.

Passo 6) Instale-o e abra o aplicativo.

\section{Considerações finais}

As propostas apresentadas pelo software visam facilitar o processo de ensinoaprendizado da lógica de programação aliada ao ensino da Matemática, em um ambiente onde a maioria dos alunos carece desta base e do incentivo para enxergar esta disciplina não mais como um obstáculo, mas como o primeiro passo no processo de aprendizagem na área da computação e afins.

O software tem uma proposta que visa uma abordagem cognitivista, pois o aluno ao visualizar o fluxo de informações consegue se aprimorar, tendo em vista que ao se utilizar de mais sentidos, o aprendizado se torna mais facilitado, por conseguinte, mais prazeroso.

Ao longo do desenvolvimento do projeto, o amadurecimento e a consolidação das propostas apresentadas foi notável, aperfeiçoando o modo Precisão e o modo Sagacidade, além de utilizar da gamificação e recompensa para conquistar tais objetivos. Almeja-se aprimorar a aplicação através da inserção de novos mecanismos, como novos modos de jogo, mesclando cada vez mais elementos de lógica de programação e da matemática, fazendo assim da aplicação um companheiro desafiador e lúdico para aqueles que iniciam na "jornada" da programação.

\section{References}

KOLIVER, C., Dorneles, R. V., Casa, M. E. 2004. Das (Muitas) Dúvidas e (Poucas) Certezas do Ensino de Algoritmos. In: XII Workshop de Educação em Computação (WEI 2004), 2004, Salvador. Anais do XXIV Congresso da Sociedade Brasileira de Computação. p. 949-960.

RODRIGUES JUNIOR, M. C. Como Ensinar Programação? Informática - Boletim Informativo Ano I ${ }^{\circ}$ 01, ULBRA, Canoas, RS, 2002.

UNITY. Unity. 5.4.0f3. San Francisco: Unity Technologies, 2004. 1 DVD-ROM. 